\title{
A Conceptual Framework for Using and Evaluating Web-Based Learning Resources in School Education
}

\author{
Said Hadjerrouit \\ University of Agder, Kristiansand, Norway
}

Said.Hadjerrouit@uia.no

\section{Executive Summary}

Web-based learning resources (WBLRs) have provided teachers with a wide range of new teaching experiences that are not possible in traditional classroom. However, little research has been done as to which approach to WBLRs is suitable to address issues that are pertinent to learning. This paper proposes a conceptual framework to explore the design and evaluation of WBLRs in school education. The paper also examines the way in which the framework is used to evaluate students' and teachers' perceptions of WBLRs by means of survey questionnaires. Before developing the framework, a literature review is undertaken to report on the state of research in the field of WBLRs. The literature review reveals a lack of design and evaluation of WBLRs in educational settings. Then, the framework is developed in three steps. First, the concept of WBLR is defined as a learning object that exists at the intersection of content, pedagogy, and technology. Second, concepts of usability are analyzed, and a definition of technical and pedagogical usability is proposed. Technical usability is a self-evident requirement, but it is not sufficient for designing pedagogically usable WBLRs. The usability concept must be extended to capture issues that are fundamental to learning. Nevertheless, technical and pedagogical usability cannot be considered as separate, disjointed activities. Finally, the context of use and evaluation is specified. The context is the totality of relationships between students and surrounding elements within a teaching and learning situation. The WBLR can be considered as an element of the context, and as such, it becomes a source of learning, by means of interaction with the students. To investigate the value of the framework, a case study is undertaken in three classes. To this end, the framework was used to inform the study, and the findings of the study were mapped back onto the framework in order to identify additional features found in classroom settings and points in the conceptual framework that did not significantly impact the case study. The main factor that impacted the design and evaluation of WBLRs was the pedagogical usability. While students and teachers globally agreed about technical usability, the findings indicate that they differed in their perceptions of pedagogical usability. In addition, the conceptual framework and the findings of the case study differed to a certain degree regarding the connectedness of some pedagogical usability criteria.

Material published as part of this publication, either on-line or in print, is copyrighted by the Informing Science Institute. Permission to make digital or paper copy of part or all of these works for personal or classroom use is granted without fee provided that the copies are not made or distributed for profit or commercial advantage AND that copies 1) bear this notice in full and 2) give the full citation on the first page. It is permissible to abstract these works so long as credit is given. To copy in all other cases or to republish or to post on a server or to redistribute to lists requires specific permission and payment of a fee. Contact 0HPublisher@InformingScience.org to request redistribution permission.
The findings also revealed the existence of cultural values connected to students' preferred choices. This factor has not been explicitly anticipated from the conceptual framework. The findings cannot be generalized due to the limited nature of the study. However, the article proposes elements of a future research work that should be taken forward to generate a more complete picture of usability is- 
sues and what constitutes WBLRs in school education.

Key words: Conceptual framework, learning theory, pedagogical usability, technical usability, Web-based learning resources, WBLRs

\section{Introduction}

The use of the Web as an educational tool has provided teachers with a wide range of new and exciting teaching experiences that are not possible in traditional classroom (Nam \& SmithJackson, 2007), such as accessing information at any time and place, online presentation of information, interactive task-based activities, effective dissemination of information, and long distance education. Besides their instructional value, WBLRs are potentially powerful tools for enhancing learning experiences and improving the learning outcomes. However, the research literature is just beginning to report on the use of WBLRs in educational settings (Combes \& Valli, 2007). Currently, it appears that WBLRs are still the domain of technical experts rather than educators and learners (Nam \& Smith-Jackson, 2007). However, the added value of WBLRs in terms of learning will come from a better understanding of pedagogical issues and not automatically from improved technology (Govindasamy, 2002; Hamid, 2002; Saade, 2003; Watson, 2001). Clearly, the design and evaluation of WBLRs must go beyond technical usability and include issues that are pertinent to learning and pedagogy.

\section{Research Goal}

The research goal of this work was to use the literature, along with a study of three actual classroom WBLRs, to develop a framework of critical elements in WBLR design and evaluation. A literature review was undertaken to report on the state of research in the field of WBLRs. Then, a conceptual framework was developed based on the literature review. Finally, to investigate the value of the framework, a case study was undertaken in three classes. To this end, the framework was used to inform the study, and the findings of the study were mapped back onto the framework in order to identify additional features found in classroom settings, and points in the conceptual framework that did not significantly impacted the case study.

\section{Literature Review}

WBLRs as educational tools offer learners access to well-structured and easily-updatable study materials, task-based activities, online resources, and tutorial support. In spite of these benefits, however, learners may be left frustrated or disappointed, because WBLRs do not sufficiently address their needs or expectations. WBLRs have been developed mainly by software designers and developers with a high level of technical expertise, but without knowledge about learners' needs (Nam \& Smith-Jackson, 2007). As a result, difficulties may arise when graphics is overemphasized to the detriment of pedagogical aspects, so that a WBLR looks attractive, but is difficult to use in educational settings (Brinck, Gergle, \& Wood, 2002). Clearly, existing WBLRs still lack a number of important issues that need to be considered in design and evaluation.

First, WBLRs are still the domain of technical and software experts rather than teachers, educators, and learners (Nam \& Smith-Jackson, 2007). As a result, most WBLRs basically emphasize technical usability as defined by Brinck, Gergle, \& Wood (2002) and Nielsen (2000). Technical usability is important to minimize the cognitive load and helps to free more resources for the learning process itself. It enables learners to easily focus on learning materials without having to make an effort to figure how to access them. However, although technical usability is a selfevident requirement for WBLRs, it is not necessarily conductive for deep learning. For instance, according to Ingram (2003), the degree and rapidity of navigation, which is a crucial characteristic of WBLRs, does not necessarily measure the educational quality of the WBLR in terms of 
learning, since the aim is to determine whether learners can effectively navigate through the WBLR, for example, the number of links learners had to follow to find specific information, perform an assignment, answer questions, or survey questionnaire. Clearly, navigation is supposed to measure task performance, not learning.

Second, to support learning, a number of researchers (Kukusska-Hulme \& Shield, 2004; Laurillard, 2002; Leacock \& Nesbit, 2007; Nokelainen, 2006) suggest that developers need to design WBLRs with suitable usability, and then tailor it more closely to meet the learners' needs, thereby implying that there is a further dimension to consider when designing WBLRs. This dimension is often called "pedagogical usability" as it is associated with aspects that are fundamental to learning. Hence, to deal with pedagogical issues, technical usability must be extended to capture elements that are pertinent to learning. However, little attention has been paid to pedagogical usability of WBLRs, which is a critical factor to the success of this technology in classroom. From the viewpoint of pedagogical usability, current WBLRs lack a number of features that would make them more flexible, interactive, motivating, and collaborative. Research literature reveals that WBLRs with advanced features are difficult to design, and therefore current systems are still limited in their pedagogical usability. Martinidale, Cates, and Qian (2005) stated that it is substantially more difficult to create WBLRs that accommodate the demands of constructivist learning. Likewise, Liu and LaMont Johnson (2005) found a lack of fit between existing WBLRs and what teachers, educators, and learners need, as well as a lack of connection between WBLR design and educational standards.

Third, the pedagogical value of WBLRs lies in helping learners discover and explore things for themselves through interactive, flexible, differentiated, and motivating activities. Unfortunately, as mentioned above, most WBLRs provide little support to achieve a high level of flexibility, interactivity, feedback, differentiation, and collaboration, diminishing the added value and indisputable character of WBLRs (Liu \& LaMont Johnson, 2005; Martinidale, Cates, \& Qian, 2005). This is because most WBLRs are developed without a previous analysis of learners' needs. Clearly, a learner-centered approach to WBLRs requires a change from teacher-centered instruction to an environment that emphasizes the learners' needs (John \& Sutherland, 2009). Indeed, a learnercentered approach, which is associated with the constructivist learning theory, offers more scope for realizing possible learning benefits than traditional instructional paradigms. However, Maddux (2005) indicated that such a change demands a massive shift in values related to school culture, teaching, and learning, as well as an intensive commitment to individualized learning. In line with this view, Belland (2009) and Jamieson-Proctor, Watson, Finger, Grimbek, and Burnett (2007) do not attribute the lack of technology integration to insufficient post-teacher education in digital skills or lack of software resources and infrastructure, which are very present in most classrooms, but to obstacles related to cultural issues and folk pedagogies formed through home, school education, and experience. These obstacles are very difficult to change, unless technology integration is of longer duration, integrated into content and methods, and incorporates pedagogical modelling.

Fourth, it follows from the above considerations that the use of WBLRs in classroom is strongly connected to teachers' epistemological orientations, personal theories and perceptions about teaching and learning processes. According to Jimoyianiis and Komis (2007), a true integration requires that teachers consider technology, content, and pedagogy not in isolation, but rather in the complex relationships in the system defined by three key components: (a) Knowledge of the pedagogy that is applicable to the specific content; (b) Knowledge of how technology can support pedagogical goals; and (c) Knowledge of how the subject matter is transformed by the application of the technology. Clearly, teachers' technical knowledge alone is not sufficient to achieve learning outcomes using WBLRs. Equally important is how WBLRs can support pedagogical goals that are set by the teacher and how the content is transformed through the technology (John \& 
Sutherland, 2009). As a result, teachers' epistemological orientations and knowledge should not be underemphasized when it comes to organize, design, implement, and evaluate pedagogical situations in classroom around WBLRs.

Fifth, in contrast to higher education, little research has been done evaluating students' and teachers' perceptions of WBLRs in school education, modalities of teaching and learning using these resources (Kay, Knaack, \& Petrarca, 2009). In addition, exhaustive instruments (e.g., Squires \& Preece, 1999) may not be suitable to evaluate WBLRs, which tend to be smaller and more numerous (Leacok \& Nesbit, 2007). Furthermore, a number of evaluation frameworks that can be used to evaluate user interfaces have been proposed (e.g., Nielsen, 1993; Rubin, 1994). But, these frameworks are intended for software environments rather than WBLRs in which learnercentered user interface systems should be developed to support users' activities. Another problem with evaluating WBLRs is that relatively few are currently being used in schools. ITU Monitor (2009) reports that the selection of digital learning resources is limited, and that designing, developing, and implementing WBLRs, which provide added value in learning and teaching, is very demanding and time consuming. Nevertheless, some schools have made considerable progress in the use of digital learning resources, but many of them still have much to do to develop and use subject-specific digital learning resources.

Summarizing, the literature review reveals a lack of design and evaluation regarding WBLRs in educational settings. This work sets out to address this by developing a conceptual framework for the identification of factors in relation to the design, use, and evaluation of WBLRs.

\section{A Framework for Designing and Evaluating WBLRs}

The process of designing and evaluating WBLRs in school education is a many-sided field of study with a number of theoretical and practical issues. Three fields are of interest for developing a conceptual framework for designing and evaluating WBLRs: the concept of WBLR and its core features, technical and pedagogical usability issues, and the context of use and evaluation.

\section{Web-Based Learning Resources: Main Features}

There is no clear and unequivocal definition of the concept of WBLR. It is difficult to distinguish the term "Web-based learning" from terms, such as "virtual learning", "technology-based learning", "network learning", "online learning", "multimedia-based learning", "Web-enhanced learning", "Internet-enabled learning", "Web-based learning environment", and similar terms. A closer look at the concept of WBLR shows that a number of features found in the research literature can be adopted. The concept is similar to "Web-based learning tools", also referred as learning objects, which is defined as "interactive Web-based tools that support learning by enhancing, amplifying, and guiding the cognitive processes of learners" (Kay et al., 2009). In addition, WBLRs include the main features of the term "Web-based learning application," which is defined by Liu and LaMont Johnson (2005) as instructional content or activity delivered through the Web that teaches a focused concept, meets specific learning objectives, provides a learner-centered context, and is an individual and reusable piece. Accordingly, WBLRs can be defined as a technology with four major features: (a) It is delivered through the Web; (b) It teaches content that meets specific learning objectives aligned with the curriculum; (c) It is designed on the basis of a learning theory and pedagogical strategy; (d) It contains reusable elements (Figure 1).

From a technological point of view, WBLRs use Web technologies and Internet services as delivery mode, that is to say HTML, URL, browsers, e-mail, and file transfer facilities, etc. WBLRs can include Web 2.0 tools, such as Wikis and Blogs, which allow collaborative and communication activities on the Web (Norton \& Hathaway, 2008). In addition to scripting languages, such as PHP and JavaScript, WBLRs incorporate multimedia applications and animations, video and au- 
dio clips, film, and graphics, and those developed with multimedia authoring software, such as Authorware, ToolBook, and Flash.

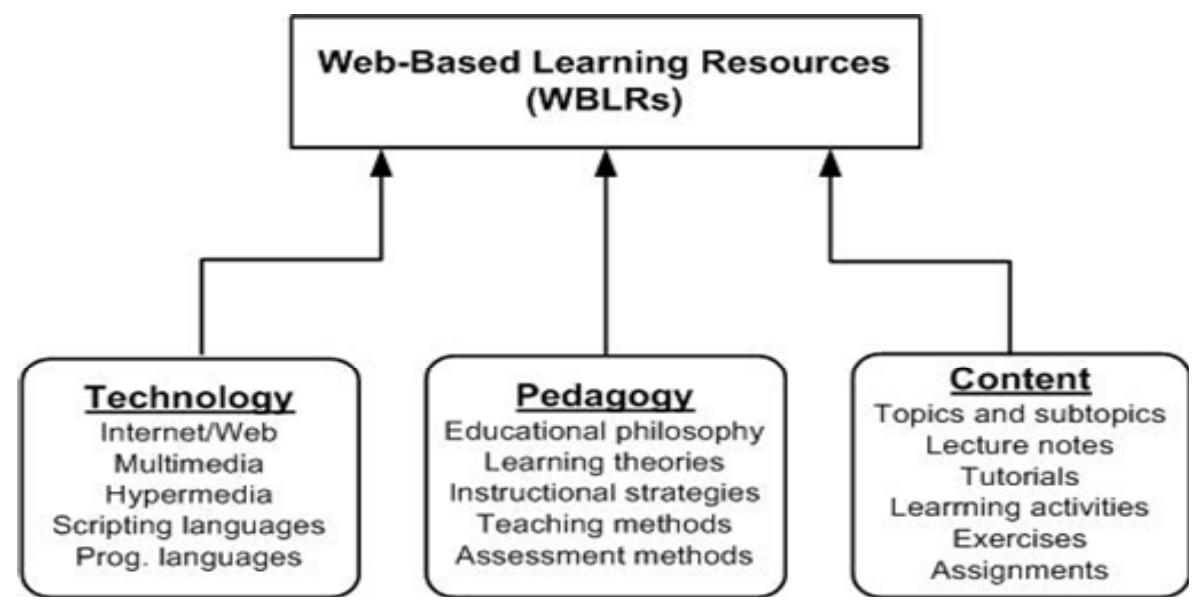

Figure 1: Web-based learning resources: Main features

From a pedagogical point of view, the design of WBLRs is embedded within a pedagogical procedure or learning theory, such as instructionism, behaviorism, cognitivism, constructivism, and collaborative learning or a combination of them (Martindale et al., 2005). Hence, WBLRs are associated with pedagogical values that potentially affect teaching and learning processes. In addition, WBLRs can be used in a context, where the teaching and learning of the subject matter takes place via a combination of classroom and Web-based learning.

From the subject matter point of view, WBLRs are computer-based implementations of a specific topic that is normally aligned with a given curriculum in school education, its objectives and competence aims. WBLRs include study material and lessons, task-based activities and exercises, examples, and eventually assessment procedures. WBLRs can also be created to support different topics of a given subject, as well as instructional material in a number of subject areas at all levels in school education.

Finally, WBLRs need to be reusable in order to suit the students' needs (Johnson \& Hall, 2007). Reusability is also useful for school subjects in different classroom contexts. It assumes that pieces or elements of WBLRs can be found to fit into another or new lesson (Strijker \& Collis, 2007). It also assumes that a given lesson or course will find WBLRs or elements of them from many Web-based resources or throughout a database repository.

\section{Usability Criteria}

The concept of usability has been defined by a number of researchers, but a complete definition is difficult to achieve outside the domain it is to be considered (Petersen, 2007; Simbulan, 2007). Nielsen $(1993,2000)$, as one of the foremost usability researchers, proposed a definition that focuses on technical usability. However, the impact of Nielsen's definition is limited when it comes to design pedagogical software. Nokelainen (2006) expanded Nielsen's definition to include pedagogical usability. Both aspects of usability are related to each other. Technical usability involves techniques for ensuring a trouble-free interaction with the software while pedagogical usability aims at supporting the learning process. The goal of technical usability is to minimize the cognitive load resulting from the interaction with the software in order to free more resources for the learning process itself. Most of the conventional usability criteria will apply to pedagogical software: the need for consistency, learner satisfaction, minimal user actions and minimal mem- 
ory load, simplicity and reduction of complexity (Nielsen, 1993; Scheidermann, 1998). The concept of pedagogical usability is related to the learning process and utility of pedagogical software.

According to these considerations, technical and pedagogical usability cannot be considered as separate, disjointed activities. On the contrary, they are strongly related to each other, and even congruent. However, this is not always true for many reasons. First, a software system that may be efficient to use, is not always easily learnt; and a software system that is easily learnt, may not always be efficient to use. Therefore, in certain cases, increased technical usability could influence negatively pedagogical usability, since high level of technical usability does not contribute necessarily to the learning outcome (Tselios, Avouris, \& Komis, 2008). Clearly, while technical usability is a self-evident requirement, it is not necessarily conductive for deep learning (Mayes \& Fowler, 1999). Deep learning is associated with the process of knowledge construction by the learners, in which experimentation offers significant learning opportunities, in stark contrast with a basic technical usability requirement (Tselios et al., 2008). It follows that pedagogical usability cannot be approached as a conventional task that can be solved only with techniques developed by work in Human-Computer Interaction (Mayes \& Fowler, 1999). This implies that pedagogical software is considered beneficial for the learners if it contributes to the learning process and not if it simply supports efficient task execution (Tselios et al., 2008). For these reasons, the concept of pedagogical usability must be re-defined and related to its learning utility (Sedig, Klawe, \& Westrom, 2001). In order to reformulate the concept, it must be directly related to theories of human learning (Elliot, Jones, \& Barker, 2002).

\section{Technical usability of WBLRs}

Technical usability is related to how a WBLR is convenient, practicable, and usable for the students. More specifically, Nielsen's factors of Web usability (Nielsen, 2000) include content, page, and site design. Page design is related to cross platform, speed of page access, and page linking. Content design depends on writing for scannability and media use. Site design is about linking and navigation. Accordingly, the following criteria are considered as important for the technical usability of WBLRs. These are divided into three generic usability criteria:

- Content design. This criterion indicates how easy it is to read the content of the WBLR and how efficient it is to access it.

- Page design. This criterion describes how easy it is to use the pages of the WBLR and associated figures, multimedia elements, logo, and illustrations.

- Site design. This criterion specifies how easy it is to access the menus, and navigate through the links and screens of the WBLR.

\section{Pedagogical usability of WBLRs}

Technical usability is a self-evident requirement, but it is not sufficient for designing pedagogically usable WBLRs. The usability concept must be extended to capture issues that are fundamental to learning. The literature on learning theories points to the fundamental differences and similarities between them (Lin \& Hsieh, 2001), but in school education, a mix of learning theories is being used. Hence, teachers must allow circumstances surrounding the learning situation to help them decide which approach to learning is the most appropriate (Karagiorgi \& Symeou, 2005). Nevertheless, teachers need to consider that WBLRs suggest more a learner-centered approach than teacher-centered methods (John \& Sutherland, 2009) in order to realize learning benefits. Designing learner-centered WBLRs requires a constructivist approach to learning and the integration of pedagogical usability issues. The concept of pedagogical usability has been addressed by Nokelainen (2006), who defined a set of ten criteria that can be applied to digital learning material: learner control, learning activity, collaborative learning, goal orientation, applicability, added value, motivation, previous knowledge, flexibility, and feedback. These criteria 
can be adapted to WBLRs with slight modifications. Accordingly, the key criteria that influence the pedagogical usability of WBLRs are as follows:

- Understandability. WBLRs should provide a well-structured description of the subject information using a clear and understandable language. The content should be wellorganized, clear, and concise so that it is easy understandable.

- Added value. The added value of WBLRs means that they offer more learning potentialities than traditional resources, such as textbooks, in terms of the potential capabilities of WBLRs such as collaboration, feedback, interactivity, and flexibility.

- Goal-orientation. This criterion is related to its learning utility and meaningfulness in terms of the learning goals set by the teacher and the curriculum.

- Time. WBLRs must allow the student to learn the subject matter within a limited, but acceptable, period of time. It should preferably take less time to learn the subject information with the WBLR than with traditional resources such as textbooks.

- Interactivity. WBLRs should provide support for interactivity through easy and userfriendly accessibility of the subject information and task-based activities. Interactivity is important because it allows students to be actively involved in problem solving.

- Multimedia. WBLRs should provide multiple representation of information using various multimedia elements, such as text, graphics, sound, animations, and video files. Taskbased activities can contain links to multimedia applications, such as games and simulations. Students should feel that their learning is enhanced through the use of multimedia.

- Motivation. The material provided by WBLRs should contain intrinsically motivating tasks and examples. It should show important aspects of the subject matter that may affect the students' learning. Motivation is goal oriented and facilitates students' higher levels of engagement with the study material.

- Differentiation. This criterion implies that WBLRs are adapted to the students' age, development, and interests. Differentiation involves fitting the subject information to the characteristics of the students, taking into account their abilities, gender, language, needs, motivation, prior knowledge, and computer skills.

- Flexibility. Flexibility means that WBLRs provide different levels of difficulty and contain diverse assignments and tasks that are tailored to all students, so that their individual differences can be taken into account.

- Autonomy. This criterion means that students are able to work on their own using WBLRs and acquire knowledge without being completely dependent on the teacher. The knowledge provided by WBLRs should be potentially powerful to enable the student to become less dependent on the teacher's assistance.

- Collaboration. This criterion means that students can work together to reach a common goal, giving them a sense of how problem solving can be performed in collaboration. This is important because learning is considered as an inherently social activity as good solutions are developed not in isolation, but in collaboration with other students.

- Variation. Students are able to use different learning resources in combination with WBLRs. Variation is important to learning, because of different students' learning styles and preferences, and various approaches and ways of learning, or because some students favor some particular methods of interacting with, while other prefer other approaches.

\section{Context of Use and Evaluation of WBLRs}

The third key element of the framework is the context of use and evaluation of WBLRs. From a practical point of view, the most appropriate approach to carefully examine the context of 
WBLRs is to look at the influencing factors connected to them. The context is the totality of relationships between the students and surrounding elements within a teaching and learning situation. This concept of context is similar to Brousseau's term of "milieu" (Brousseau, 1998), where learning is described as emerging from exchanges between the students and a "milieu" organized with teaching intentions. Accordingly, milieu is everything in the situation the learners can act on. It can be divided into two categories: Material and non material milieu. The material milieu includes a number of elements:

- The subject matter, its content, topics and subtopics, task-based activities, assignments, exercises, and problem statements taught in the classroom.

- The curriculum and its objectives, main subject areas, basic skills, including computer skills, competence aims in the subject, and subject assessment.

- Infrastructure (technical and non-technical), software tools available, number and place of computers, student/PC-ratio in the classroom.

- Textbooks and other study material such as teaching notes or electronic study material.

The non material milieu consists of the stakeholders involved in school education:

- Fellow learners in the classroom and their characteristics, such as age, knowledge level, gender, interests, needs, motivations, and computer skills.

- School teachers' profiles and pedagogies, ICT qualifications, and attitudes towards ICT.

- School leaders and ICT policies, decision makers and actors supporting ICT integration.

- Trainee teachers as designers and developers of WBLRs.

The mileu forms the very basis for the process underlying the design, development, use, and evaluation of WBLRs. The milieu may change for the student when introducing a new element the WBLR, because learning and teaching processes are then mediated by the technology. According to Brousseau (1998), learning occurs by means of interaction between the student and the "milieu". Learning happens through adaptation of the student to the milieu. This view is consistent with Piaget's work that considers learning as an adaptation process to a milieu (Piaget, 1972). The WBLR can be considered as an element of the milieu, and as such, it becomes a source of learning, by means of interaction with the student (Figure 2).

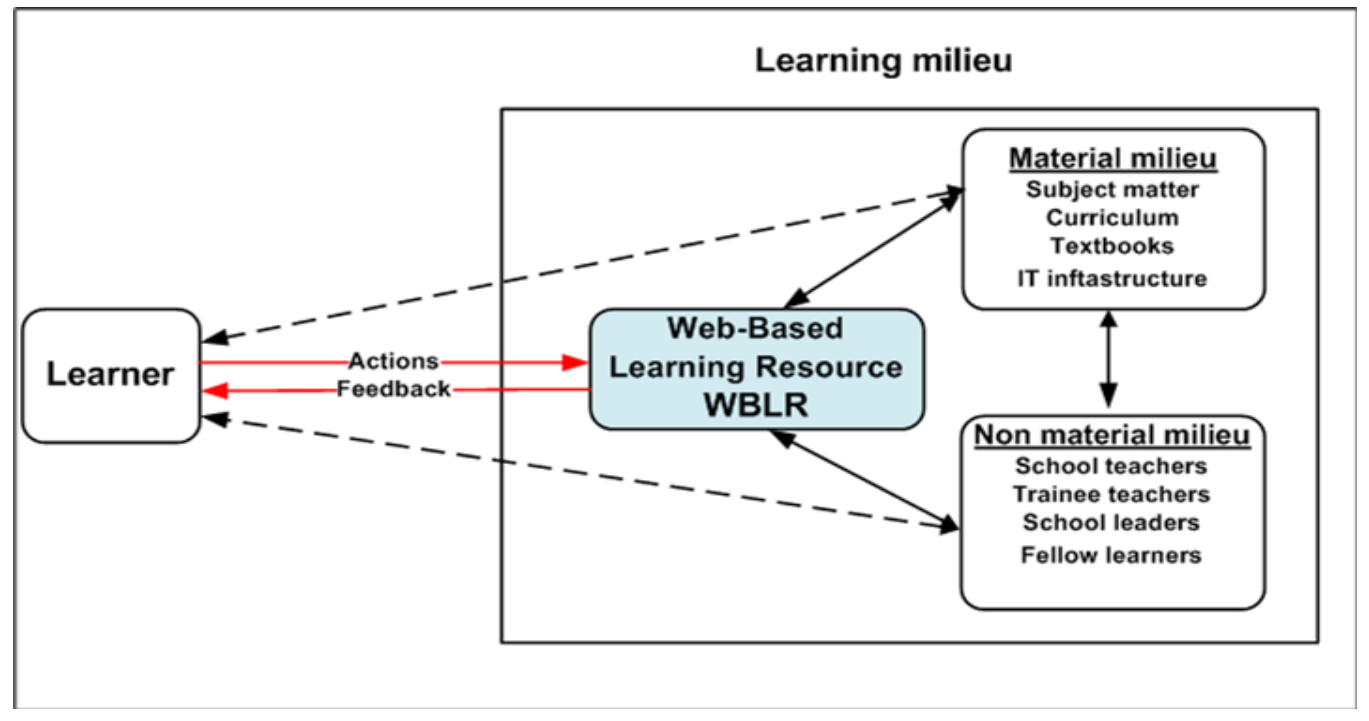

Figure 2: Context of use of WBLRs and relationships between various elements 
The nature of the interaction between learners and WBLRs is dependent on the instructional approach and epistemological orientation adopted by the teacher. WBLRs, by their very nature, require a change from teacher-centered methods to constructivist or learner-centered approaches in order to achieve learning benefits (John \& Sutherland, 2009). However, the added value of WBLRs in terms of learning can be taken in account only if it is well perceived by the teacher.

\section{The Resulting Conceptual Framework}

The conceptual framework shown in Table 1 gives an overview of the factors and key points that emerge from the three fields of interest for WBLRs: main features, usability criteria, and context of use and evaluation. In line with Teartle (2004), the framework is set up with a collection of questions instead of statements to highlight issues to consider in design and evaluation.

\begin{tabular}{|c|c|}
\hline \multicolumn{2}{|c|}{ Table 1: Conceptual framework for identifying the key points of WBLRs } \\
\hline FACTORS \& KEY POINTS & ISSUES AND QUESTIONS \\
\hline $\begin{array}{cl}\text { WBLR features } \\
\text { - } & \text { Pedagogy } \\
\text { - } & \text { Technology } \\
\text { - } & \text { Content }\end{array}$ & $\begin{array}{l}\text { Does the school/class have pedagogical and learning strategies? } \\
\text { Is the existing software infrastructure able to support WBLRs? } \\
\text { Which content of the subject matter is relevant? }\end{array}$ \\
\hline $\begin{array}{c}\text { Usability criteria } \\
\text { Technical usability } \\
\text { - Content design } \\
\text { - } \text { Page design } \\
\text { - Site design } \\
\text { Pedagogical usability } \\
\text { - Understandability } \\
\text { - Added value } \\
\text { - Goal-orientation } \\
\text { - Time } \\
\text { - Interactivity } \\
\text { - Multimedia } \\
\text { - Motivation } \\
\text { - Differentiation } \\
\text { - Flexibility } \\
\text { - Autonomy } \\
\text { - Collaboration } \\
\text { - Variation }\end{array}$ & $\begin{array}{l}\text { Is the content easy to understand? } \\
\text { Does the WBLR bring something better than existed already? } \\
\text { Are the learning goals set by the teacher and curriculum? } \\
\text { Is the time needed for learning taken into consideration? } \\
\text { How good is the WBLR's feedback on the students' actions? } \\
\text { Does the WBLR combine a number of multimedia elements? } \\
\text { Is the WBLR adapted to the students' characteristics? } \\
\text { Can the WBLR be tailored to the student? } \\
\text { Does the WBLR appear open and flexible? } \\
\text { Does the WBLR support autonomy of learning? } \\
\text { Is the WBLR designed to support collaboration? } \\
\text { Is the WBLR designed to support variation? }\end{array}$ \\
\hline $\begin{array}{l}\text { Context of use/evaluation } \\
\text { Non material milieu } \\
\text { - Textbooks } \\
\text { - } \quad \text { IT infrastructure } \\
\text { - Curriculum } \\
\text { - Subject matter } \\
\text { Material milieu } \\
\text { - Fellow learners } \\
\text { - School teachers } \\
\text { - Trainee teachers } \\
\text { - School leaders } \\
\end{array}$ & $\begin{array}{l}\text { Is it intended to use textbooks in combination with the WBLR? } \\
\text { Does the IT infrastructure provide sufficient support? } \\
\text { Does the WBLR fit the curriculum? } \\
\text { How is the subject implemented through the WBLR? } \\
\text { Is it intended to use the WBLR collaboratively? } \\
\text { What is the school teacher's attitude to the WBLR? } \\
\text { What is the role of trainee teachers in the use and evaluation? } \\
\text { What is the school policy regarding WBLRs? }\end{array}$ \\
\hline
\end{tabular}




\section{Case Study}

This case study was situated within teacher education in collaboration with three middle school classes, where trainee teachers developed WBLRs. The unit of study was the learning of school subjects using WBLRs. The goal was twofold. First, analyze the students' and teachers' perceptions of WBLRs. Second, outline some implications for the design and evaluation of WBLRs.

\section{Participants}

Data from the case study came from three cohorts of participants:

- Sixty-five students (30 females and 35 males) between 14-16 years from three different classes within the same school.

- Three school teachers from three different classes within the same school. The teachers knew their students, since they worked with them over a relatively long period of time.

- Three teams of trainee teachers from the University as designers of WBLRs.

\section{WBLRs}

The subjects of the WBLRs were chosen by school teachers in collaboration with trainee teachers. The situation in which the WBLRs were used is listed in Table 2. Each row refers to the class, the subject, the number of lessons of 45 minutes, and the number of participating students and school teachers. The subjects were taught in three different classes in a middle school.

\begin{tabular}{|clcc|}
\hline \multicolumn{4}{c|}{ Table 2: Subjects associated with the WBLRs } \\
\hline CLASS & SUBJECT & DURATION & NO. STUDENTS \\
\hline Class 1 & Language and culture & $2 \times 45 \mathrm{~min}$ & 18 \\
Class 2 & Water - A vital resource & $2 \times 45 \mathrm{~min}$ & 24 \\
Class 3 & Volcanoes, tsunami, and earthquakes & $2 \times 45$ min & 23 \\
\hline
\end{tabular}

The WBLRs were developed by three teams of trainee teachers, who used a user-centred approach to the development process. The WBLRs were developed in collaboration with the university teacher, who provided academic supervision, on the one hand, and school teachers who informed the trainee teachers about curricular and pedagogical issues, on the other hand. Collaboration occurred by means of e-mail, phone, and during meetings with the school teachers.

\section{Data Collection Methods}

Data collection methods consisted of two survey questionnaires: Student and teacher questionnaire. The aim was to measure the students' and teachers' perceptions of WBLRs.

\section{Student survey questionnaire}

Data from the first questionnaire were completed by 65 students from three different classes. The questionnaire was delivered to the students at the end of the teaching sessions with the WBLRs. To measure their responses, a five-point Likert scale from 1 to 5 was used, where 1 was coded as the lowest and 5 as the highest ( $5=$ "Strongly agree"; 4 = "Agree"; $3=$ "Neither Agree or Disagree"; 2 = "Disagree"; $1=$ "Strongly Disagree"). The students were asked to respond by placing a cross " $X$ " in the appropriate box using the scale provided. The questionnaire (Appendix A) focused on what the students had to say about the technical and pedagogical usability of WBLRs. In 
addition, the students were asked to respond to two open-ended questions and comment what they like and dislike about the WBLRs, and what they think should be improved.

\section{Teacher survey questionnaire}

The second questionnaire was completed by 3 school teachers after the WBLRs were used in classroom (Appendix B). The survey was used to collect data about the following themes:

- The number of Web pages visited by the students

- Teachers' preparation before the use of WBLRs

- Teaching issues and WBLRs

- Curriculum and WBLRs

- Technical usability of WBLRs

- Pedagogical usability of WBLRs

In addition, the teachers were asked to respond to two open-ended questions and comment what they like and dislike about the WBLRs, as well as what they think should be improved.

\section{Data Analysis Methods}

Both quantitative and qualitative methods were used for evaluating the WBLRs. Accordingly, particular attention was devoted to the following five data analysis methods:

1. Students' perceptions of technical and pedagogical usability of WBLRs.

2. Students' comments about what they like and dislike about the WBLRs, and what they think should be improved.

3. Teachers' perceptions of technical and pedagogical usability of WBLRs, as well as some additional issues related to teaching and curricular issues.

4. Teachers' comments about what they like and dislike about the WBLRs, what they think should be improved, and some additional issues related to teaching and curricular issues.

5. Relationships between students' and teachers' perceptions of WBLRs.

\section{Findings}

The findings describe the students' and teachers' perceptions of WBLRS in their respective classes, and the relationships between them.

\section{Student Perceptions}

The analysis of the students' perceptions of WBLRs shows that the following results have been achieved for the two major themes of the work: technical and pedagogical usability.

\section{Technical usability}

Students' perceptions of technical usability of WBLRs are as follows (The first three themes in Appendix C). Sixty-four percent strongly agreed and 32.3\% agreed $(\mathrm{N}=65)$ that it is easy to use the WBLRs. Forty-six percent strongly agreed and $43.1 \%$ agreed that it is easy to understand the symbols, logo, figures, pictures, and illustrations. Finally, $60.9 \%$ strongly agreed and $34.4 \%$ agreed that it is easy to use the menus, and navigate through the screens of the WBLRs.

The descriptive statistics analysis shows the distribution of the data across the range of values of the five-point scale, including the mean and standard deviation (Table 3). It appears from the analysis that the data support the students' perceptions of technical usability of WBLRs. 


\begin{tabular}{|l|c|c|c|c|c|}
\hline \multicolumn{5}{|c|}{ Table 3: Descriptive statistics for the technical usability criteria } \\
\hline & N & MIN & MAX & MEAN & STD. DEVIATION \\
\hline Page design & 65 & 3 & 5 & 4.62 & .550 \\
\hline Content design & 65 & 3 & 5 & 4.35 & .672 \\
\hline Site design & 64 & 3 & 5 & 4.56 & .588 \\
\hline
\end{tabular}

\section{Pedagogical usability}

Students' perceptions of the pedagogical usability of WBLRs are as follows. The results (the twelve last themes in Appendix C) show that 46.2\% strongly agreed and 33.8\% agreed that the content of the WBLRs is easy to understand. In addition, 36.9\% strongly agreed and $35.4 \%$ agreed that it is better to use such WBLRs to learn the subject matter than textbooks.

Likewise, $27.7 \%$ strongly agreed and $29.2 \%$ agreed that they learned mostly by using the WBLRs. However, it must be taken into consideration that $36.9 \%$ of the students neither agreed nor disagreed. Then, $22.2 \%$ indicated that they strongly agreed and $34.9 \%$ agreed that it takes less time to learn the subject matter using the WBLRs than textbooks. Likewise, it must be taken into consideration that $31.7 \%$ of the students neither agreed nor disagreed.

Moreover, $27.7 \%$ strongly agreed and $50.8 \%$ agreed that the task-based activities are interactive, exciting, instructive, and informative. Then, most students $(81.3 \%)$ strongly agreed or agreed that animations, graphics, and pictures provide support for the understanding of the subject matter.

With regard to the motivational dimension, $27.0 \%$ of the students strongly agreed and $52.4 \%$ agreed that the WBLRs are exciting to use, motivating, and interesting. The evaluation of differentiation indicates similar results. More than $70 \%$ strongly agreed or agreed that the WBLRs are adapted to their age, development, and interest.

Furthermore, $32.8 \%$ strongly agreed and $25.0 \%$ agreed that the study information offered by the WBLRs is flexible as it provided different levels of difficulty and could be tailored to all students. With regard to autonomy, the findings point out that almost $89 \%$ did not ask the teacher for help when they used the WBLRs.

In contrast to autonomy, only $3.2 \%$ strongly agreed or agreed that they collaborated with fellow students when they used the WBLRs. In stark contrast, $84.1 \%$ disagreed or strongly disagreed that they collaborated with fellow students. Finally, the overwhelming majority $(93.8 \%)$ did not use other learning resources than the WBLRs.

The descriptive statistics analysis shows the distribution of the data across the range of values of the five-point scale, including the mean and standard deviation (Table 4). As for the technical usability, it appears that the data are consistent with the percentages of students' responses. 
Table 4: Descriptive statistics for the pedagogical usability criteria

\begin{tabular}{|lccccc|}
\hline & N & MIN & MAX & MEAN & STD. DEVIATION \\
\hline Understandability & 65 & 2 & 5 & 4.22 & .875 \\
Added value & 65 & 1 & 5 & 4.02 & .960 \\
Goal-orientation & 65 & 1 & 5 & 3.77 & .965 \\
Time & 63 & 1 & 5 & 3.67 & .984 \\
Activity & 65 & 2 & 5 & 4.03 & .770 \\
Multimedia & 64 & 2 & 5 & 4.22 & .786 \\
Motivation & 63 & 2 & 5 & 3.95 & .906 \\
Differentiation & 64 & 2 & 5 & 4.00 & .836 \\
Flexibility & 64 & 2 & 5 & 3.80 & 1.026 \\
Autonomy & 62 & 2 & 5 & 4.50 & .741 \\
Collaboration & 63 & 1 & 5 & 1.71 & .869 \\
Variation & 64 & 1 & 5 & 1.31 & .753 \\
\hline
\end{tabular}

\section{Correlations between technical and pedagogical usability}

To complete the analysis of the data collected it is important to look at the interactions between the variables of the usability criteria. This is the result of correlation analysis (Bryman, 2004). A correlation measures the common variation of two variables. It does not necessarily mean that one variable causes another. According to Gorard (2001), an explanation of correlations needs to involve theoretical considerations and the triangulation of knowledge from other data sources.

Table 5 shows that all the variables of pedagogical usability were positively correlated with those of technical usability, except for the variables "collaboration" and "variation", which were negative. Positive correlations mean that the variation in the variables of pedagogical usability and those of technical usability are closely connected, but that there is some influence of other variables in the extent to which they vary. A possible explanation of these positive correlations is that technical usability has a positive impact on pedagogical usability. This does not necessarily mean there is a cause-effect relationship between them. However, it is reasonable to believe that technical usability could have influenced pedagogical usability.

Furthermore, correlation analysis shows that the relationship between two of the variables of pedagogical usability and those of technical usability were negative. This was the case of the variable collaboration and variation. A possible explanation of the negative correlations is that there is a tendency such that, the higher the technical usability is, the less likely the students need to collaborate and use other resources, but that other variables clearly influence collaboration and the use of other resources. A possible explanation is that the technical usability had insignificant impact on collaboration and use of other resources, but that the influence of the teacher on collaboration and use of other resources was by far greater than the technical usability of WBLRs. 


\begin{tabular}{|c|c|c|c|}
\hline \multicolumn{4}{|c|}{ Table 5: Correlations between technical and pedagogical usability } \\
\hline & PAGE DESIGN & CONTENT DESIGN & SITE DESIGN \\
\hline Understandability & $.824^{* *}$ & $.799^{* *}$ & $.640^{* *}$ \\
\hline Added value & $.692^{* *}$ & $.815^{* *}$ & $.842^{* *}$ \\
\hline Goal-orientation & $.743^{* *}$ & $.852^{* *}$ & $.751^{* *}$ \\
\hline Time & $.668^{* *}$ & $.730^{* *}$ & $.603^{* *}$ \\
\hline Activity & $.729^{* *}$ & $.795^{* *}$ & $.753^{* *}$ \\
\hline Multimedia & $.744^{* *}$ & $.836^{* *}$ & $.795^{* *}$ \\
\hline Motivation & $.651^{* *}$ & $.653^{* *}$ & $.567^{* *}$ \\
\hline Differentiation & $.663^{* *}$ & $.667^{* *}$ & $.542^{* *}$ \\
\hline Flexibility & $.640^{* *}$ & $.777^{* *}$ & $.544^{* *}$ \\
\hline Autonomy & $.759^{* *}$ & $.683^{* *}$ & $.614^{* *}$ \\
\hline Collaboration & $-.517^{* *}$ & $-.681^{* *}$ & $-.704^{* *}$ \\
\hline Variation & $-.565^{* *}$ & $-.595^{* *}$ & $-.563^{* *}$ \\
\hline
\end{tabular}

\section{Student Comments}

Basically, most students agreed that they liked the WBLRs both with respect to technical and pedagogical usability, but there are some differences between the classes.

Class 1: Language and culture. Most students in this class liked the content provided by the WBLR, especially the combination of written and recited text with audio recording. A typical comment was: "It was very good that we did not need to read all the text, but just to listen to the audio recording. Everything was well arranged and well done. The content of the text was varied, informative, and easy to understand." Most students preferred the WBLR to textbooks. Only one student expressed concerns about the difficulty of the topic. Even if the majority of the students were satisfied with the WBLR, some students expected more interactivity.

Class 2: Water - a vital resource. Globally, the students in this class pointed out very clearly that they liked very much this kind of WBLR, especially sound recording, quizzes, and the content. A typical student's response was: "I liked that there was audio recording of the text and motivating quizzes. It was easier to understand the text without reading. Nice quizzes." Most students did not think that the WBLR should be improved, but some expected more interactive exercises. One commented that the crossword exercises were not quite understandable. Another student did not like a blue colour as background.

Class 3: Volcanoes, tsunami, and earthquakes. Likewise, the students in class 3 liked very much the WBLR, especially the content, animations, and quizzes. However, most students think that there is a need for more interactive animations and recited text with audio recording. One typical student's comment was: "I liked very much the animations. There were fine and easy to understand. I liked audio recording of the text, but you should have done this for all the text." Some students expressed some concerns about the time needed to download graphics and the technical design of the video films, which did not always work as expected. 


\section{Teacher Perceptions}

First of all, all teachers indicated that the WBLRs were aligned with the curriculum and associated subjects. They also reported that the WBLRs were tied to teaching and that the technical design was good and adapted to the subject matter. They pointed out that it was easy to navigate through the menus, screens, and links of the WBLRs.

Second, the teachers think that it is important for the teaching process to combine WBLRs with textbooks. They also believed that the use of different resources stimulate learning, because some students prefer information technologies, while other like more traditional ways of instruction. Finally, all teachers indicated that the students learned both from WBLRs and textbooks.

Furthermore, they reported that the amount of text and figures provided by the WBLRs is suitable, and they think this helped the students to learn more. They also believed that the learning activities (exercises and quizzes) helped the students to learn more about the subject matter. Then, they pointed out that the WBLRs were motivating and interesting to work with, because they were tailored to the students' age, development, and interests. The WBLRs were motivating because of their intrinsic characteristics, and not because of their novelty. Teachers were not quite familiar with all the technicalities of WBLRs, but this technology was not new to them.

In addition, all teachers liked the technical design, as well as animations, video, and audio recording, but they did not think that quizzes can cover the entire scale of students' knowledge. They believed that there is a need for more interactive and collaborative activities.

Finally, the teachers agreed that the level of interaction is suitable, but they varied in their opinion when it comes to the specificity of the interaction. The first teacher (project: Language and culture) indicated that he could not expect a high degree of interaction, because the students needed to focus more on reading and listening. The second teacher (project: Water - vital resource) thinks that text, voice, film, and quizzes are appropriate enough for individual interaction, but not for student collaboration. The third teacher (project: Volcanoes, tsunami, and earthquakes) pointed out that the degree of interaction was not high, without explaining the reasons.

\section{Teacher Comments}

All teachers evaluated the WBLRs that the students used in their respective classes. Their comments were mostly positive but critical concerning some issues. The following teachers' comments are related to open-ended questions no. 17 and 18 of the questionnaire, that is to say what they like and dislike about the WBLRs, and what should be improved.

Teacher 1 (Project: Language and culture): "I liked very much the audio recording, both from text and dialect trial. It is fine that all students can work with the subject matter individually and have the possibility to acquire knowledge. Adapted learning." "The web site is very good."

Teacher 2 (Project: Water - a vital resource): "Good layout. Good with recited text and varied degree of difficulty of content, both with regard to text and task-based activities. The WBLR will never cover the entire scale of students' knowledge through quizzes; other activities must be offered, as well as further work and specialization. Good with links." "It takes time to download audio recording, but this is fine as long as the students are aware of it. Specialized tasks?"

Teacher 3 (Project: Volcanoes, tsunami, and earthquakes): "Well arranged. Clear. Good layout. Not much about the composition of the globe. Some information about the huge energy within the globe is needed." "Could be improved by showing a cut through the globe and the continuous and dynamic flow of magma. Show examples of mountains that are formed by collisions (Himalaya)." 
From the comments it follows that teachers were satisfied with the degree of interactivity provided by the WBLRs. However, they expected more interactivity and more focused and specialized task-based activities than just quizzes or similar tasks. It also appears that they liked audio recording and recited text. In addition, it seems that they were aware of the fact that WBLRs cannot always cover the entire knowledge level of the students. Also time for downloading audio recording was a critical issue.

Teachers also commented that they were aware of individual differences with respect to students' learning styles and learning effect of WBLRs: "Students are different, some learn with textbooks, other with WBLRs." They also think that both WBLRs and textbooks are instructive as this comment indicates: "I think that both are equally instructive. It is good with variation." Finally, all teachers found that animations supported learning. One of the teachers' comments was: "I believe that the animations made the subject topic easier to understand."

\section{Similarities and Differences between Student and Teacher Perceptions}

A careful analysis of students' and teachers' comments shows that their perceptions of technical usability were very similar as both believed that the WBLRs were technically well-designed. Likewise, there is a high degree of similarity regarding pedagogical usability, except for learning activities, the role of other learning resources, and collaboration. Their perceptions of the motivational power of the WBLRs show similar tendencies. There was also a high degree of satisfaction from both sides with respect to audio recording and animations. Most students and all teachers expressed very clearly that they preferred more audio recording and animations rather than text.

However, as mentioned above, students and teachers differed in their perceptions of interactivity, variation of resources, and collaboration. While most students were satisfied with the provided learning activities, teachers expected advanced, preferably more differentiated, activities. In addition, while most students did not attach much attention to the use of other resources than the WBLRs themselves, teachers felt that WBLRs were not better than textbooks in terms of learning outcomes. Finally, contrary to teachers, who perceived the value of collaboration, students did not consider collaborative activities as important to their learning.

\section{Discussion}

In this section, a summary of findings and some implications for the design and evaluation of WBLRs are presented. The limitations of the work are discussed as well.

\section{Summary of Findings}

The findings can be summarized as follows. First, most students agreed that the technical usability of WBLRs was well-designed and implemented. They also indicated that the level of pedagogical usability was high. Furthermore, most students think that they were motivated when they used WBLRs. Moreover, students also believed that WBLRs showed a high degree of differentiation. Finally, most students indicated that they did not collaborate with their fellow students, nor did they ask for teacher help or use textbooks.

Second, all teachers indicated that the criteria underlying the technical usability were welldesigned. Teachers also agreed that the dimensions of the pedagogical usability were globally achieved. Moreover, teachers reported that the degree of students' independence from teacher assistance was high, in stark contrast to the low level of collaboration with fellow students and the low degree of variation with regard to learning resources. Teachers' comments are consistent with the findings. 
Third, results suggest that students and teachers had similar perceptions about the technical and pedagogical usability of WBLRs, except for interactivity, variation, and collaboration. While teachers expected more variation, collaboration, and activities, students were globally satisfied with the degree of implementations provided by WBLRs.

\section{Implications for the Design and Evaluation of WBLRs}

While students and teachers globally agreed about technical usability, the findings indicate that they differed in their perceptions of pedagogical usability with regard to three criteria: interactivity, collaboration, and variation. Accordingly, students and teachers had different perceptions of the capabilities of the WBLRs to support learning. Looking at these dimensions of pedagogical usability some implications can be drawn.

First, both students and teachers pointed out that the degree of interactivity was satisfying. However, teachers expected more interactivity and more focused and specialized task-based activities than just quizzes or similar tasks. They felt that the tasks provided were not sufficient to really engage the students in constructivist learning as they do not cover the entire knowledge level of a number of students, who particularly demonstrated strong motivation in the topics. Accordingly, enhanced interactivity can be achieved through increased differentiation, flexibility, and intrinsically motivating tasks. Hence, differentiation is clearly connected to interactivity. It includes different ways of interacting with the WBLRs while giving special consideration to differentiation between students according to their ability, preferred learning styles, knowledge level, and the different speeds at which they learn. Motivation, which is closely linked both to interactivity and differentiation, measures the degree of engagement with the subject matter when using the WBLRs. Student motivation is a subjective phenomenon, but one that is important in keeping students engaged with the subject matter. Increased motivation can be achieved through selfregulation, performance, or learning goals, as well as extrinsic or intrinsic goal orientation, such as meaningful study material provided by the WBLRs.

Second, teachers were not satisfied with the degree of collaboration between students, because they felt that the students did not work together to reach a common goal. The idea of collaboration fits well with the socially situated learning theory, which assumes that learning occurs as learners improve and reflect on their understanding of the subject matter through discussion with fellow students (Vygotsky, 1978). Accordingly, it is important that WBLRs contribute to increase the learning by collaboration in a higher degree and allow the students to engage in levels of activity that could not be managed alone using the WBLR without collaboration with fellow students. However, WBLRs can contribute to collaboration only if students and teachers perceive the value of collaborative learning. From the technological point of view, enhanced collaboration can be achieved through the integration of Web 2.0 technologies that allow collaborative and communication activities on the Web.

Third, the criterion of autonomy measures the degree of students' independence from the teacher. The findings reveal that most students worked independently from the teacher and were satisfied with the degree of autonomy provided by the WBLRs. The criterion of autonomy can reveal the quality of the learning material provided by the WBLR. Nevertheless, WBLRs are potentially limited in their capabilities to support learning, and beyond a certain level, they cannot contribute to the learning process alone, unless students are engaged in level of activity that they cannot manage alone without the assistance of a more knowledgeable person. Vygostky's theory of Zone of Proximal Development (ZPD) can be a useful construct to understand the tension between learning independence and collaboration with others (Bowler, Andrew, Large, Beheshti, \& Nesset, 2005). The concept of ZPD is the "distance between the actual developmental level as determined by independent problem-solving and the level of potential development as determined through problem solving under adult guidance or in collaboration with more capable peers" (Vy- 
gotsky, 1978, pp. 86). Students' learning development, according to Vygotsky, should not be assessed by what they can learn independently with the WBLR alone, but rather by what they can do with the assistance of others.

Fourth, in contrast to students, who did not perceive variation as an element that stimulates learning, teachers still considered textbooks as equally important as WBLRs. In other words, they still see the importance of WBLRs, but they consider them as supplementary aids in addition to textbooks. Two implications can be drawn from these considerations. On the one hand, teachers do not need to radically change their pedagogy if WBLRs and textbooks have the same pedagogical value. Teachers would perceive WBLRs as a neutral technology - without added value - that cannot radically affect the teaching and learning context. Hence, instructivist ways of teaching through textbook-based activities will still be the focus in a Web-based learning environment, in stark contrast to the potentialities of WBLRs. On the other hand, if the added value of WBLRs is taken into consideration and well-perceived by teachers, then they need to make drastic changes in their ways of teaching. The added value of WBLRs is in the form of the potentialities this technology offers to learners, e.g., interactivity, feedback, and differentiation, in contrast to textbooks that are more rigid and static in their use. Hence, WBLRs can only be useful if task-based activities are adapted to the capabilities of the technology. Tasks should not be a direct translation of study materials found in textbooks. They must be interactive and flexible according to students' individual differences and provide the students with immediate feedback that stimulates the learning motivation. The added value of WBLRs is associated with a constructivist approach to learning. Teachers need then to make a shift from instructivism to constructivism. This shift requires that the teachers' role changes from transmitter of knowledge to facilitator of learning.

Finally, the added value of WBLRs lies in enhanced cultural usability, which is to a certain degree implicitly connected both to technical usability through graphics, colours, and symbols, and pedagogical usability through the students' characteristics, e.g. their age, preferred learning styles, and language. However, the catalogue of usability criteria does not explicitly address cultural usability, which is a relatively new research perspective (Li, Sun, \& Zhang 2007). Cultural values are connected to folk pedagogies formed through home, school education, society, and experience. A number of students expressed their preferred cultural values through the comments they made by means of survey questionnaires. As a result, WBLRs cannot be considered as a value-neutral technology (Gadanidis \& Schindler, 2006). On the contrary, cultural values are embedded within WBLRs, which in turn can potentially affect teaching and learning processes, how students use WBLRs, and what they learn from them.

\section{Limitations}

The results of this work cannot be generalized because of various factors, such as a single experiment of limited duration, the small sample size $(\mathrm{N}=65)$, the small number of classes $(\mathrm{N}=3)$, three school teachers, and three different topics. Hence, difficulty generalizing is due to the limited nature of the study, but also in significant part because of the unique nature of every WBLR.

Although it was easy to compare the WBLRs across the three classes according to the criteria of technical and pedagogical usability, it was not possible to draw general conclusions about how the WBLRs should work in all classes. However, the primary objective of this work was not to generalize to other cases, but to investigate the pedagogical potentialities of WBLRs in some classes and how this technology could be used to enhance students' learning. Hence, the most important is that the WBLRs improve over the long term, when students and teachers repeatedly use and evaluate WBLRs in classroom. Unfortunately, school teachers have rarely the time and all the skills needed to improve the design of WBLRs. They have also little control over usability testing, unless the school uses professional designers and usability specialists to assist them. 
Beyond the generalization issue, the second limitation is the method used to measure usability issues, that is to say, survey questionnaires and comments. Although most students were satisfied with the WBLRs, it does not necessarily imply that the digital resources were usable for all students, because usability cannot be separated from testing the WBLRs with representative users. In addition, it is questionable whether the students were able to understand and reasonably answer all the questions of the survey questionnaire. Moreover, one single questionnaire may not be sufficient to adequately measure the students' perceptions of usability issues. Hence, various, both qualitative and qualitative methods, and their triangulation, may be more powerful to measure the students' perceptions of WBLRs.

Finally, the third limitation that can promote or hinder the success of WBLRs in classroom is time. Indeed, research reveals that information technology can provide positive learning opportunities, but it takes time (Hayes, 2007; Teartle, 2004). Accordingly, the overall impression is that the use and evaluation of WBLRs is highly dependent upon the availability of time to think deeply about pedagogical changes. Time plays also an important role for the students in terms of learning effect of WBLRs compared with printed material. Hence, new cycles of design and evaluations may be necessary to measure the pedagogical value of WBLRs.

\section{Conclusions with Respect to the Framework}

The main research goal of this work was to use the literature, along with a study of three actual classroom WBLRs, to develop a framework of critical elements in WBLR design and evaluation. To this end, the framework was used to inform the study, and the findings of the study were mapped back onto the framework in order to identify additional features found in classroom setting and points in the conceptual framework that did not significantly impacted the case study. As a result of this mapping the following conclusions can be drawn.

First, the main factor that impacted the design and evaluation of WBLRs was the pedagogical usability. While students and teachers globally agreed about pedagogical usability, they differed in their perceptions regarding some criteria: interactivity, collaboration, and variation. The findings highlighted the importance of constructivist learning, both individually and collaboratively, for the design and evaluation of WBLRs, and the added value of this technology compared with traditional learning resources. These findings are compatible both with elements of the conceptual framework and literature review.

Second, with regard to the relationships between the criteria of pedagogical usability, the conceptual framework and the findings of the case study differed to a certain degree. In the study, a certain connectedness of the criteria was found regarding interactivity, motivation, and differentiation, on the one hand, and autonomy and collaboration, on the other hand. However, there was little or no indication of connectedness of criteria in the conceptual framework, except that technical and pedagogical usability cannot be considered as separate or disjointed activities.

Third, in the findings there was a certain emphasis on some elements of the context of use as expressed by the framework through the concept of "milieu", but in lesser degree than in the framework, probably because the survey questionnaire did not focus on all elements of the milieu. Moreover, the findings revealed the existence of cultural values connected to students' preferred choices and ways of learning. This factor, which is important for design and evaluation, has not been explicitly anticipated from the conceptual framework.

Future work will focus on the refinement of the conceptual framework and associated usability concepts, both pedagogical and cultural. It is also important to further investigate factors that influence the integration of WBLRs into classroom, and the context of use and evaluation as well. Finally, it may be necessary to refine the instruments for measuring both teachers' and students' 
perceptions of WBLRs to ensure their validity and reliability, and completed with supplementary, both quantitative and qualitative methods.

\section{References}

Belland, B. R. (2009). Using the theory of habitus to move beyond the study of barriers to technology integration. Computers \& Education, 52, 353-364.

Brinck, T., Gergle, D., \& Wood, S. D.(2002). Usability for the web: designing Web sites that work. San Francisco, CA: Morgan Kaufman.

Bowler, L., Andrew, Large, A., Beheshti, J., \& Nesset, V. (2005). Children and adults working together in the zone of proximal development: A concept for user-centered design. Proceedings of Annual CAIS/ACSI conference 2005. Retrieved December 20, 2009 from: http://www.caisacsi.ca/proceedings/2005/bowler_2005.pdf

Brousseau, G. (1998). Theory of didactical situations. London: Kluwer Academic.

Bryman, A. (2004). Social research methods. Oxford: University Press.

Combes, B., \& Vali, R. (2007). The future of learning objects in educational settings. In K. Harman \& A. Koohang (Eds.), Learning objects: Applications, implications, \& future directions (pp.423-461). Santa Rosa, CA: Informing Science Press.

Elliott, G. J., Jones, E., \& Barker, P. (2002). A grounded approach to modeling learnability of hypermedia authoring tools. Interacting with Computers, 14, 547-574.

Gadanidis, G., \& Schindler, K. (2006). Learning objects, type II applications, and embedded pedagogical models. Computers in the Schools, 21(1), 19-32.

Gorard, S. (2001). Quantitative methods in educational research: The role of numbers made easy. London: Continuum.

Govindasamy, T. (2002). Successful implementation of e-learning: Pedagogical considerations. The Internet and Higher Education, 4, 287-299.

Hamid, A. A. (2002). E-Learning: Is it the "e" or the learning that matters? The Internet and Higher Education, 4, 311-316.

Hayes, D. N.A. (2007). ICT and learning: Lessons from Australian classrooms. Computers \& Education, 49, 385-395.

Ingram, A. (2003). Usability of alternative web course structures. Computer in the Schools, 19(3), 33-47.

ITU Monitor (2009). The digital state of affairs in Norwegian schools. Retrieved October 17, 2009 from: http://www.itu.no/ITU+Monitor.9UFRDSXH.ips

Jamieson-Proctor, R., Watson, G., Finger, G., Grimbek, \& Burnett, P.C. (2007). Measuring the use of information and communication technologies (ICTs) in the classroom. Computers in the Schools, 24(1), 167-184.

Jimoyiannis, A., \& Komis, V. (2007). Examining teachers' beliefs about ICT in education: Implications of a teacher preparation programme. Teacher Development, 11(2), 149-173.

Johnson, K., \& Hall, T. (2007). Granularity, reusability and learning objects. In A. Koohang \& K. Harman (Eds.), Learning objects: Theory, praxis, issues, and trends (pp. 181-207). Santa Rosa, CA. Informing Science Press.

John, P., \& Sutherland, R. (2009). Teaching and learning with ICT: New technology, new pedagogy? Education, Communication \& Information, 4(1), 101-107.

Karagiorgi, Y., \& Symeou, L. (2005). Translating constructivism into instructional design: Potential and limitations. Educational Technology \& Society, 8(1), 17-27. 
Kay, R., Knaack, L., \& Petrarca, D. (2009). Exploring teachers perceptions of web-based learning tools. Interdisciplinary Journal of E-Learning and Learning Objects, 5, 27-50. Retrieved June 25, 2009 from: http://www.ijello.org/Volume5/IJELLOv5p027-050Kay649.pdf

Kukulska-Hulme, A., \& Shield, L. (2004). Usability and pedagogical design: Are language learning Web sites special? Proceedings of ED-MEDIA 2004, 4235-4242.

Laurillard, D. (2002). Rethinking university teaching: A conversational framework for the effective use of learning technologies $\left(2^{\text {nd }}\right.$ ed.). London: Routledge.

Leacock, T. L. \& Nesbit, J. C. (2007). A framework for the quality of multimedia resources. Educational Technology \& Society, 10(2), 44-59.

Li, H., Sun, X., \& Zhang, K. (2007). Culture-centered design: Cultural factors in interface usability and usability tests. Proceedings of IEEE Societie's ACIS International Conference on Software Engineering, Artificial Intelligence, Networking, and Parallel/Distribute Computing (pp. 1084-1088). Washington, DC: IEEE Computer Society.

Lin, B., \& Hsieh, C. (2001). Web-based teaching and learner control: A research review. Computers \& Education, 37(3-4), 377-386.

Liu, L., \& LaMont Johnson, D. (2005). Web-based resources and applications. Computer in the Schools, 21(3), 31-147.

Maddux, C. D. (2005). The Web in K-12 education. Computers in the Schools, 21(3), 149-165.

Martinidale, T., Cates, W. M., \& Qian, Y. (2005). Analysis of recognized Web-based educational resources. Computers in the Schools, 21(3), 101-117.

Mayes, J. T., \& Fowler, C. J. (1999). Learning technology and usability: A framework for understanding courseware. Interacting with Computers, 11(5), 485-497.

Nam; C. S., \& Smith-Jackson, T. L. (2007). Web-based learning environment: A theory-based design process for development and evaluation. Journal of Information Technology Education, 6, 23- 44. Retrieved June 22, 2009 from: http://www.jite.org/documents/Vol6/JITEv6p023-043Nam145.pdf

Nielsen, J. (1993). Usability engineering. Boston, MA: Academic Press.

Nielsen, J. (2000). Designing Web usability: The practice of simplicity. Indianapolis: New Riders.

Nokelainen, P. (2006). An empirical assessment of pedagogical usability criteria for digital learning material with elementary school students. Educational Technology \& Society, 9(2), 178-197.

Norton, P., \& Hathaway, D. (2008). On Its Way to K-12 classrooms, Web 2.0 goes to graduate school. Computers in Schools, 25(3), 163-180.

Petersen, D. (2007). Usability theory, practice and evaluation for learning objects. In K. Harman \& A. Koohang (Eds.), Learning objects: Applications, implications, \& future directions (pp.337-370). Santa Rosa, CA: Informing Science Press.

Piaget, J. (1972). The psychology of the child. New York: Basic Books.

Rubin, J. (1994). Handbook of usability testing: How to plan, design, and conduct effective tests. New York, NY: John Wiley \& Sons.

Saade, R. G. (2003). Web-based educational information system for enhanced learning, EISEL: Student assessment. Journal of Information Technology Education, 2, 267-278. Retrieved June 25, 2009 from http://www.jite.org/documents/Vol2/v2p267-277-26.pdf

Scheidermann, B. (1998). Designing the user interface. New York, NY: Addison-Wesley.

Sedig, K., Klawe, M., \& Westrom, M. (2001). Role of interface manipulation style and scaffolding on cognition and concept learning in learnware. ACM Transactions on Computer-Human Interaction, 8(1), 34-59. 
Simbulan, M. S. (2007). Learning objects' user interface. In K. Harman \& A. Koohang (Eds.), Learning objects: Applications, implications, \& future directions. (pp. 259-336). Santa Rosa, CA: Informing Science Press.

Squires, D., \& Preece, J. (1999). Predicting quality in educational software: Evaluating for learning, usability and the synergy between them. Interacting with Computers, 11, 467-483.

Strijker, A., \& Collis, B. (2007). The influence of context on the future of learning objects. In K. Harman \& A. Koohang, (Eds.), Learning objects: Theory, praxis, issues, and trends (pp. 83-112). Santa Rosa, CA. Informing Science Press.

Teartle, P. (2004). A theoretical and instrumental framework for implementing change in ICT in education. Cambridge Journal of Education, 34(3), 331-351.

Tselios, N., Avouris, N., \& Komis, V. (2008). The effective combination of hybrid usability methods in evaluating educational applications of ICT: Issues and challenges. Education and Information Technologies, $13,55-76$.

Vygotsky, L. S. (1978): Mind and society: The development of higher mental processes. Cambridge, MA: Harvard University Press.

Watson, D. M. (2001). Pedagogy before technology. Re-thinking the relationship between ICT and Teaching. Education and Information Technologies, 6(4), 251-266. 


\section{Appendix A \\ Student Survey Questionnaire}

Female Male

Are you a female or male?

Place a cross in the box.

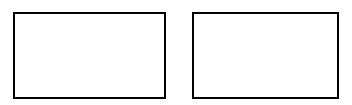

Answer by placing a cross in the appropriate box:

\begin{tabular}{|c|c|c|c|c|c|}
\hline & $\begin{array}{l}\text { Strongly } \\
\text { Agree }\end{array}$ & Agree & $\begin{array}{l}\text { Neither } \\
\text { Agree nor } \\
\text { Disagree }\end{array}$ & Disagree & $\begin{array}{l}\text { Strongly } \\
\text { Disagree }\end{array}$ \\
\hline 1. It is easy to use the WBLR. & & & & & \\
\hline $\begin{array}{l}\text { 2. It is easy to understand the symbols, logo, } \\
\text { figures, pictures, and illustrations. }\end{array}$ & & & & & \\
\hline $\begin{array}{l}\text { 3. It is easy to use the menus and screenshots, and } \\
\text { navigate through the WBLR. }\end{array}$ & & & & & \\
\hline 4. The content of the WBLR is easy to understand. & & & & & \\
\hline $\begin{array}{l}\text { 5. It is more instructive to use such WBLRs to } \\
\text { learn the subject matter than textbooks. }\end{array}$ & & & & & \\
\hline 6. I learn mostly from using this WBLR. & & & & & \\
\hline $\begin{array}{l}\text { 7. It takes less time to learn the subject matter } \\
\text { using the WBLR than the textbook. }\end{array}$ & & & & & \\
\hline $\begin{array}{l}\text { 8. The task-based activities of the WBLR are } \\
\text { interactive, exciting, instructive, and } \\
\text { informative. }\end{array}$ & & & & & \\
\hline $\begin{array}{l}\text { 9. Animations, graphics, and pictures provide } \\
\text { support for understanding the subject matter. }\end{array}$ & & & & & \\
\hline $\begin{array}{l}\text { 10. The WBLR is exciting to use, motivating, and } \\
\text { interesting. }\end{array}$ & & & & & \\
\hline $\begin{array}{l}\text { 11. The WBLR is adapted to my age, development, } \\
\text { and interests. }\end{array}$ & & & & & \\
\hline $\begin{array}{l}\text { 12. The WBLR provides different levels of } \\
\text { difficulty, and can be tailored to all students. }\end{array}$ & & & & & \\
\hline $\begin{array}{l}\text { 13. I do not ask the teacher for help when I use the } \\
\text { WBLR. }\end{array}$ & & & & & \\
\hline 14. I ask my fellow students when I use the WBLR. & & & & & \\
\hline 15. I use textbooks when I work with the WBLR. & & & & & \\
\hline
\end{tabular}

16. Describe shortly with your own words what you like and dislike about the WBLR.

17. Describe shortly with your own words what you think should be improved with the WBLR. 


\section{Appendix B Teacher Survey Questionnaire}

1. Describe shortly which topic and content pages of the WBLR your students visited.

2. Describe what preparations you did before the students used the WBLR.

3. Do you think that the WBLR is tied to teaching?
O Yes
- No

4. Do you think that the WBLR is related to the curriculum?

- Yes

O No

Why / Why not? Explain.

5. What do you think about the quality of the technical design (layout, structure, page design, logo, writing, colors, etc.)?
○ Difficult
- Average
- Easy

6. Do you think that the design of the WBLR is adapted and tied to the subject matter?

O Yes

O No

Why / Why not. Explain.

7. What do you think about the use of the menus, screens, and navigation through the WBLR?

- Difficult

- Average

O Easy

8. What do you think about teaching the subject using a WBLR in relation to using a textbook?

O I think it is more instructive to use such WBLRs than textbooks.

O I think both are instructive. Variation is important.

- I like to teach using a textbook.

9. What do you think the student learn mostly from?

O I think the students learn mostly from using such WBLRs.

O I think students learn equally from both. Variation is important.

- I think students learn mostly from textbook-based teaching. 
10. Do you think that the WBLR contains too much or too little text?
- Toо much
- Suitable
- Too little

11. Do you think that the WBLR contains too much or too little graphics?
- Tоо тисh
- Suitable
O Too little

12. What do you think about the animations?
O I think the animations made the lessons easier to understand
O I think the animations made the lessons more difficult to understand
- I think the animations were fine, but unnecessary.

13. Do you think that the WBLR provides a high degree of interaction?
- Yes
O No

Why / Why not. Explain.

14. Describe what do you think about the degree of activity of the WBLR.
- High
O Average
O Low

15. Do you think that the WBLR is exciting, and interesting?
- Yes
- No

Why / Why not. Explain.

16. Do you think that the WBLR is adapted to the students' age, development, and interests?
O Yes
O No

Why / Why not. Explain.

17. Describe what you like and dislike about the WBLR.

18. Describe what you think should be improved with the WBLR. 


\section{Appendix C \\ Student Survey Results (in percent)}

\begin{tabular}{ll|} 
& Female \\
Are you a female or male? & \\
Place a cross in the box. &
\end{tabular}

Answer by placing a cross in the appropriate box:

\begin{tabular}{|c|c|c|c|c|c|}
\hline & $\begin{array}{l}\text { Strongly } \\
\text { Agree }\end{array}$ & Agree & $\begin{array}{l}\text { Neither } \\
\text { Agree nor } \\
\text { Disagree }\end{array}$ & Disagree & $\begin{array}{l}\text { Strongly } \\
\text { Disagree }\end{array}$ \\
\hline 1. It is easy to use the WBLR. & 64.60 & 32.30 & 3.10 & 0.0 & 0.0 \\
\hline $\begin{array}{l}\text { 2. It is easy to understand the symbols, logo, figures, } \\
\text { pictures, and illustrations. }\end{array}$ & 46.20 & 43.10 & 10.80 & 0.0 & 0.0 \\
\hline $\begin{array}{l}\text { 3. It is easy to use the menus and screenshots, and } \\
\text { navigate through the WBLR. }\end{array}$ & 60.90 & 34.40 & 4.70 & 0.0 & 0.0 \\
\hline 4. The content of the WBLR is easy to understand. & 46.20 & 33.80 & 15.40 & 4.60 & 0.0 \\
\hline $\begin{array}{l}\text { 5. It is more instructive to use such WBLRs to learn } \\
\text { the subject matter than textbooks. }\end{array}$ & 36.90 & 35.40 & 21.50 & 4.60 & 1.50 \\
\hline 6. I learn mostly from using this WBLR. & 27.70 & 29.20 & 36.90 & 4.60 & 1.50 \\
\hline $\begin{array}{l}\text { 7. It takes less time to learn the subject matter using } \\
\text { the WBLR than the textbook. }\end{array}$ & 22.20 & 34.90 & 31.70 & 9.50 & 1.60 \\
\hline $\begin{array}{l}\text { 8. The task-based activities of the WBLR are } \\
\text { interactive, exciting, instructive, and informative. }\end{array}$ & 27.70 & 50.80 & 18.50 & 3.10 & 0.0 \\
\hline $\begin{array}{l}\text { 9. Animations, graphics, and pictures provide } \\
\text { support for understanding the subject matter. }\end{array}$ & 42.20 & 39.10 & 17.20 & 1.60 & 0.0 \\
\hline $\begin{array}{l}\text { 10. The WBLR is exciting to use, motivating, and } \\
\text { interesting. }\end{array}$ & 27.00 & 52.40 & 9.50 & 11.10 & 0.0 \\
\hline $\begin{array}{l}\text { 11. The WBLR is adapted to my age, development, } \\
\text { and interests. }\end{array}$ & 31.20 & 40.60 & 25.00 & 3.10 & 0.0 \\
\hline $\begin{array}{l}\text { 12. The WBLR provides different levels of difficulty, } \\
\text { and can be tailored to all students. }\end{array}$ & 32.80 & 25.00 & 31.20 & 10.90 & 0.0 \\
\hline $\begin{array}{l}\text { 13. I do not ask the teacher for help when I use the } \\
\text { WBLR. }\end{array}$ & 62.90 & 25.80 & 9.70 & 1.60 & 0.0 \\
\hline 14. I ask my fellow students when I use the WBLR. & 1.60 & 1.60 & 12.7 & 34.90 & 49.20 \\
\hline 15. I use textbooks when I work with the WBLR. & 1.60 & 1.60 & 3.10 & 14.10 & 79.70 \\
\hline
\end{tabular}

16. Describe shortly with your own words what you like and dislike about the WBLR.

17. Describe shortly with your own words what you think should be improved with the WBLR. 


\section{Biography}

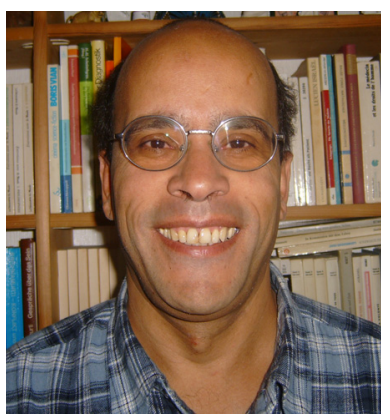

Said Hadjerrouit received the MS and $\mathrm{PhD}$ degrees in Software Engineering and Artificial Intelligence from the Technical University of Berlin (Germany), in 1985 and 1992, respectively. He joined University of Agder, Kristiansand (Norway) in 1991. He is currently an Associate Professor of Computer Science at the Faculty of Technology and Sciences. He has been in the teaching profession for 28 years. He has extensive experience in teaching object-oriented programming, Web engineering, software development, databases, didactics of informatics, ICT in mathematics education, ICT and learning. His research interests include object-oriented software development, software engineering education, didactics of informatics, ICT in mathematics education, e-Learning, web-based learning resources, Web 2.0 technologies and social software. Hadjerrouit has published over 80 papers in international journals and conference proceedings. Web: http://home.uia.no/saidh/ 